\title{
Attitudes to the disease and therapy in patients with chronic Ph-negative myeloproliferative neoplasms: results of the physician and patient surveys in Russia as a part of International Landmark Study
}

\author{
Elena V. Morozova ${ }^{1}$,'Maria V. Barabanshchikova ${ }^{1}$, Tatyana I. Ionova ${ }^{2}$, Boris V. Afanasyev ${ }^{1}$ \\ ${ }^{1}$ RM Gorbacheva Research Institute of Pediatric Oncology, Hematology and Transplantation, Pavlov University, St. Petersburg, \\ Russia \\ ${ }^{2}$ Saint Petersburg State University Hospital, St. Petersburg, Russia
}

Prof. Dr Sci Tatyana I. Ionova, Saint Petersburg State University Hospital, Fontanka Emb 154, 198103, St. Petersburg, Russia
Phone: +7 (962) 7101711

E-mail: tation16@gmail.com

Citation: Morozova EV, Barabanshikova MV, Ionova TI, Afanasyev BV. AAttitudes to the disease and therapy in patients with chronic Ph-negative myeloproliferative neoplasms: results of the physician and patient surveys in Russia as a part of International Landmark Study. Cell Ther Transplant 2020; 9(2): 28-39.

\section{Summary}

The aim of this paper was to present evaluation and synthesis of data derived from a survey of Russian patients and physicians, performed as a part of the international Landmark study for the emerging market countries designed to specify problems and areas of concern in management of patients with chronic Ph-negative myeloproliferative neoplasms (MPN). The online survey forms were filled by 40 adult patients with $\mathrm{Ph}(-)$ MPNs (PV, 42.5\%; MF, 37.5\%; ET, 20\%) and 30 physicians with sufficient experience in the $\mathrm{Ph}(-)$ MPNs treatment. As a part of this survey, patients and physicians answered questions related to perception of the disease symptoms and their impact on quality of life, daily activities and work productivity of patients, as well as their attitude to main treatment goals and various aspects of the patient-physician communication. The results revealed a number of differences between patient and physician perception of the disease and treatment, thus complementing the data of the Landmark Survey in other countries. It was shown that the patients with different variants of $\mathrm{Ph}(-)$ MPNs encounter sufficient disease-related difficulties in everyday life, impaired quality of life and reduced work productivity. Lack of coincidence revealed between the physician and patient assessment of the disease burden and treatment indicates the need for new ways of improving quality of clinical care provided to this category of patients. Further research in this area would be an important step towards implementation of patient-centered $\mathrm{Ph}(-)$ MPN treatment programs in Russian Federation.

\section{Keywords}

Myeloproliferative neoplasms, chronic, Ph-negative, physician and patient survey, symptoms, quality of life, patient-centered treatment programs. 


\section{Introduction}

Over the past decade, international hematological community has been actively engaged in clinical research to standardize medical treatment of patients with chronic $\mathrm{Ph}$-negative myeloproliferative neoplasms (MPNs) and improve the quality of care for this category of patients [1-5].

To identify the problems and areas of concern in management of the $\mathrm{Ph}(-)$ MPN patients, a large-scale Landmark Survey of patients and physicians was initiated in USA in $2014[6,7]$. A total of $813 \mathrm{Ph}(-)$ MPN patients and 457 physicians who treated this cohort participated in this survey. The results of this study were reported for each of the most common $\mathrm{Ph}(-)$ MPNs, i.e., myelofibrosis (MF), polycythemia vera $(\mathrm{PV})$ and essential thrombocythemia (ET) in the following sections: understanding of the disease diagnosis by patients and physicians; symptoms experienced by patients and their impact on daily activities, as reported by patients and physicians; disease burden with relation to the patient's quality of life and work productivity reported by patients and physicians; patient's and physician's attitudes to the treatment goals; and perception of bilateral physician-patient relationships [8]. The independent responses submitted by patients and physicians were used to find distinct similarities or differences between MF, PV, and ET. In 2016, the project became international, and the electronic survey forms were completed by $\mathrm{Ph}(-)$ MPN patients and hematologists who treated these diseases in Australia, Japan, Canada, Germany, Italy, and the UK [9]. The data collected in this survey enabled the researchers to evaluate perception of the physical, psychological, social and other problems that $\mathrm{Ph}(-) \mathrm{MPN}$ patients face in their daily life, and to improve the awareness of hematologists about these problems.

The next stage of this project took place in 2018, as a research program, to conduct an online survey of $560 \mathrm{Ph}(-)$ MPN patients and 260 hematologists in the emerging market countries: China, Turkey, Russia, Taiwan, South Korea, and Saudi Arabia $[10,11]$ The results of this survey, along with previous studies conducted in 2014-2016, are of importance for improving $\mathrm{Ph}(-) \mathrm{MPN}$ medical care and developing standardized approaches to diagnosis and treatment of these chronic disorders. The project could potentially promote the multidisciplinary efforts, working together with patients and their relatives, in order to maximize effects of the $\mathrm{Ph}(-) \mathrm{MPN}$ therapy.

The aim of this paper is to analyze and systematize the data from the Russian patient and physician survey arranged as part of the Landmark Survey in the emerging market countries.

\section{Patients and methods}

Forty $\mathrm{Ph}(-) \mathrm{MPN}$ patients and physicians residing in the Russian Federation took part in the international Landmark Survey between September and November 2018. The criteria for engaging a physician for the survey were as follows: (1) managing of least 2 patients with MF, 5 patients with $\mathrm{PV}$, and 5 patients with ET over last 12 months; (2) professional experience in hematology over 1 year; at least $25 \%$ of patients treated by the physician had to have hematological disorders.
The patients with MF, PV and ET aged 18 years and older were enrolled with the physician at their routine clinic visits. Patients were eligible to complete the survey, being, however, excluded if they were participating in any clinical trials.

The survey checklists consisted of the following sections: for patients - patient demographics, patient awareness and perception of symptoms, impact of disease on daily living, work productivity/activity impairment, disease history and treatment, patient satisfaction, disease information availability; for physicians - physician demographics and caseload, patient disease burden, patient management and treatment decisions, physician perceptions [11]. This was an exploratory survey; no any special standardized questionnaires were applied during the survey.

Before completing the survey, patients and physicians consented to participate in the project. Both patients and physicians participated in the online survey independently of each other. To keep confidentiality, all physicians and patients were assigned identification numbers. Before the start of the survey, all the participants were given instructions on the procedure and principles of electronic questionnaire completion. The survey took 25-30 minutes.

The results survey are presented as descriptive statistics with estimation of mean values, standard deviations, and percentages for each position tested. Analyses were conducted in Stata statistical software version 16.0 or later (StataCorp, 2015. Stata statistical software: Release 16 (College Station, TX, StataCorp LP)). Where missing values were found in a particular variable, any participant with missing values was removed from all pieces of analysis where that variable was used. However, patients and physicians removed from one piece of analysis were still eligible for inclusion in other analyses. It was expected that the base of patients and physicians would vary from variable to variable for this reason.

\section{Results}

\section{Characteristics of the patients and attending physicians}

Overall, 40 patients with $\mathrm{Ph}(-)$ MPNs and 30 physicians completed the online survey. The characteristics of the patients included in the survey are summarized in Table 1 . The distribution by diagnosis was as follows: PV, 42.5\%; MF, 37.5\%, and ET, $20 \%$ of patients. Twelve $(80 \%)$ of the 15 MF patients were diagnosed with primary MF. Mean age of the patients at the time of diagnosis was $54.9 \pm 9.7$ years, duration of the disorder was $3.0 \pm 2.2$ years. Hence, their mean age at the survey was $57.9 \pm 10.4$ years. Diabetes mellitus (38\% of ET patients), congestive heart failure (20\% of MF patients), peptic ulcer (18\% of PV patients), deep vein thrombosis (18\% of PV patients) and liver disease (18\% of PV patients) were the most common comorbidities in this group.

It is worth of note that over a half of the patients (55\%) exhibited symptoms for a year prior to diagnosis, $17.5 \%$ during two years, and almost $1 / 3$ of patients (27.5\%) felt them over two years prior to the clinical diagnosis.

Of 30 physicians participating in the survey, 24 (80\%) were hematologists, and 6 (20\%) were hematologists-oncologists. 
Table 1. Clinical and demographic characteristics of the patients

\begin{tabular}{|c|c|c|c|c|}
\hline & $\begin{array}{l}\text { Total group } \\
(\mathrm{n}=40)\end{array}$ & $\begin{array}{l}\text { MF } \\
(n=15)\end{array}$ & $\begin{array}{l}\text { PV } \\
(n=17)\end{array}$ & $\begin{array}{l}\text { ET } \\
(n=8)\end{array}$ \\
\hline $\begin{array}{l}\text { Average age at the time of the survey, } \\
\text { years }( \pm S D)\end{array}$ & $57.9 \pm 10.4$ & $61.9 \pm 9.8$ & $56.1 \pm 11.7$ & $54.0 \pm 6.4$ \\
\hline $\begin{array}{l}\text { Average age at the time of the diagno- } \\
\text { sis, years }( \pm S D)\end{array}$ & $54.9 \pm 9.7$ & $58.9 \pm 9.0$ & $52.9 \pm 10.8$ & $51.8 \pm 6.7$ \\
\hline Women, \% & 52.5 & 47.0 & 53.0 & 62.5 \\
\hline $\begin{array}{l}\text { Disease duration since diagnosis, years } \\
( \pm \text { SD) }\end{array}$ & $3.0 \pm 2.2$ & $3.0 \pm 2.5$ & $3.2 \pm 2.3$ & $2.3 \pm 1.0$ \\
\hline \multicolumn{5}{|c|}{ Onset period of the symptoms before diagnosis, \% } \\
\hline$<6$ months & $7.5 \%$ & $7 \%$ & $6 \%$ & $13 \%$ \\
\hline 6-12 months & $47.5 \%$ & $47 \%$ & $47 \%$ & $50 \%$ \\
\hline $1-2$ years & $17.5 \%$ & $19.5 \%$ & $12 \%$ & $25 \%$ \\
\hline$>2$ years & $27.5 \%$ & $26.5 \%$ & $35 \%$ & $13 \%$ \\
\hline
\end{tabular}

Approximately half of the physicians (47\%) had 3 to 15 years of professional experience, $40 \%$ had 15 to 25 years, and $13 \%$ had experience of 25 to 33 years. Over the period of 12 months preceding the survey, each of the physicians treated, on average, $10 \mathrm{MF}$ cases, $16 \mathrm{PV}$ patients, and $14 \mathrm{ET}$ cases. $63 \%$ of physicians worked in regional clinic hospitals, $30 \%$ in specialized referral centers, and 7\%, at the University clinics.

\section{Symptoms in $\mathrm{Ph}(-)$ MPN patients}

At diagnosis, the patients reported fatigue (63\%) and weakness (53\%) as the most common $\mathrm{Ph}(-)$ MPN symptoms. Other symptoms post-diagnosis included pruritus (33\%) and night sweats (30\%). On average, $\mathrm{Ph}(-)$ MPN patients mentioned seven symptoms ever experienced during their illness. The MF patients complained about eight symptoms, compared with six symptoms usually reported by PV and ET patients.

The five most common symptoms reported by MF, PV and ET patients over the past 12 months are listed in Figure 1. Over half of the MF patients reported fatigue (80\%), weakness $(67 \%)$, and night sweats $(60 \%)$. Worth of note, not all patients believed these symptoms were related to the disease. In particular, the patients did not associate fatigue, weakness, and night sweats with the disease in 33\%, $40 \%$ and $56 \%$ cases, respectively. As for PV symptoms, 59\% of patients felt weakness, and $41 \%$ experienced fatigue and pruritus. Hence, $20 \%$ and $14 \%$ of the patients did not relate weakness and fatigue, respectively, to specific symptoms of their disease. Meanwhile, all the patients believed that pruritus was associated with the disease. $50 \%$ of ET patients experienced fatigue and numbness/tingling. Of note, all the patients associated fatigue with the disease; as for numbness/tingling, $12.5 \%$ of patients did not associate this symptom with the disease. At the same time, most physicians (69\%) believed that the vast majority of the patients associated their symptoms with myeloproliferative disease.

The patients also evaluated severity of their symptoms in the past 12 months using a 10-point numerical rating scale
A

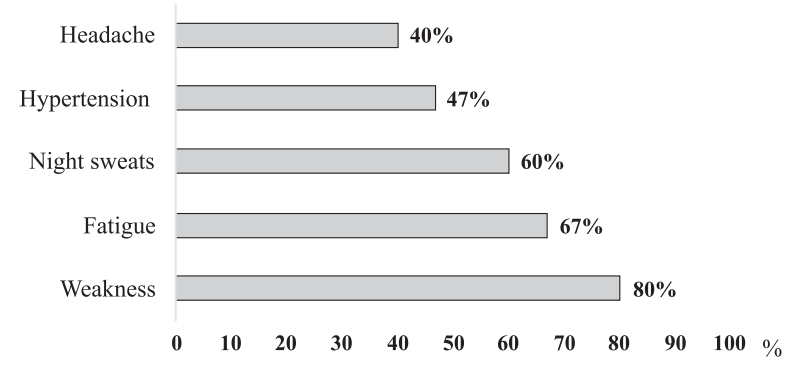

B

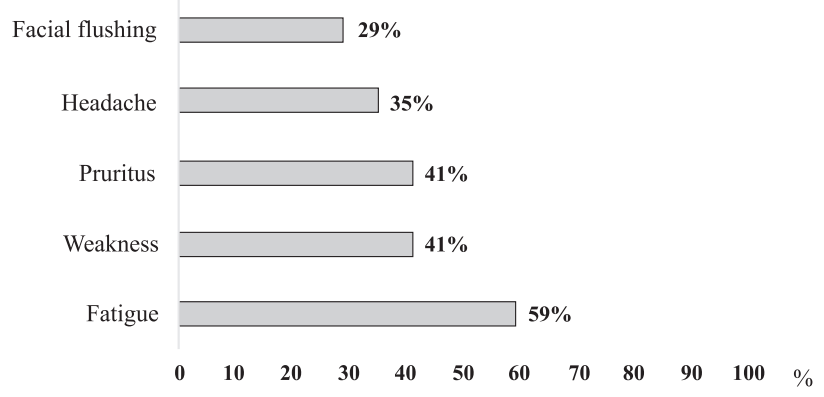

C

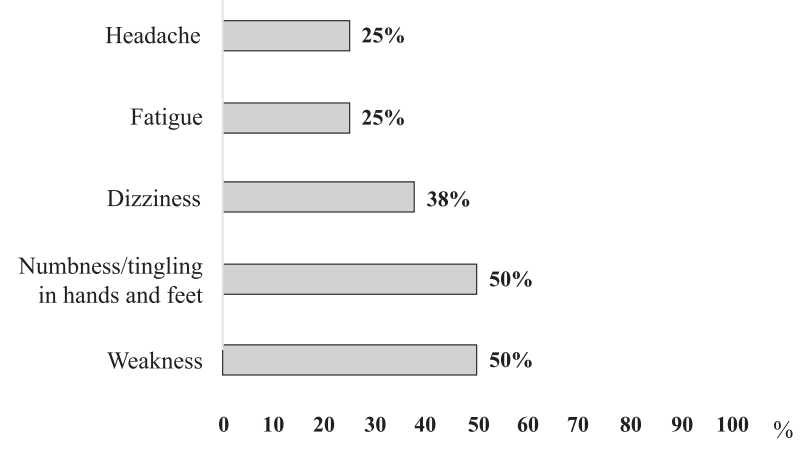

Figure 1. Most commonly reported symptoms across all Ph(-) MPNs during last 12 months: A - myelofibrosis, $B$ - polycythemia vera, and C - essential thrombocythemia 
(NRS). Some symptoms were severe: $\geq 7$ points on the NRS scale. Patients with $\mathrm{Ph}(-) \mathrm{MPN}$ reported the following severe symptoms: fatigue $(n=18)$, weakness $(n=15)$, headache $(n=9)$, night sweats $(n=8)$, abdominal pain $(n=7)$, fever $(n=5)$, dizziness $(n=5)$, bone pain $(n=2)$, nose bleeding $(\mathrm{n}=2)$ and facial flushing $(\mathrm{n}=2)$.

Attending physicians also answered some questions about symptoms in their patients. They were asked to list five most significant symptoms for the patients with each type of $\mathrm{Ph}(-)$ MPNs. For MF, the physicians mentioned fatigue (72\%), unintentional weight loss (59\%), weakness (45\%), abdominal discomfort (34\%), and night sweats (31\%). Of note, only half of the physicians, when compared to their patients, reported night sweats in these cases. In PV, physicians pointed to itching (59\%), headaches $(45 \%)$, hypertension $(41 \%)$, facial flushing and numbness/tingling in hands and feet (38\%). Moreover, as opposed to patients, none of the physicians mentioned weakness or fatigue. For ET, the physicians noted fatigue (59\%), nasal bleeding and thrombotic events clot $(48 \%)$, headaches (37\%), and weakness (33\%). Unlike patients, physicians did not mention numbness/tingling. As evidenced by the above data, there are discrepancies in the patient and physician perception of the most significant symptoms experienced by $\mathrm{Ph}(-)$ MPN patients, while $77 \%$ of physicians believed that they have correctly assessed the symptom burden.

As a separate task, both physicians and patients were asked to choose from the list of symptoms experienced by patients those traits that, according to the patient, were most likely to be resolved ( 1 to 3 ). The MF patients mentioned fatigue (47\%) and pruritus (33\%); physicians chose weakness (45\%) and fatigue (31\%). Patients with PV pointed to pruritus (41\%), whereas, in opinion of physicians, pruritus (52\%) and hypertension (48\%) were most likely to be resolved. As for ET, the patients chose fatigue (38\%), while physicians highlighted fatigue, tingling in the hands/feet, and predisposal for thrombosis (44\%).

These discrepancies in the physician and patient description of the symptoms that are most significant to patients can be partially explained using the survey data, with regard of the physician's strategies when discussing symptoms and general well-being during the patients' clinical visit. The majority of patients mentioned in the survey that the physicians were interested in their symptoms and overall well-being. Patients noticed the following: during the clinic visit, attending physician was actively interested in their well-being and symptoms ( $55 \%$ of patients); the doctor asked them about specific, most important symptoms (25\%); the physician expected patients to report their concerns (15\%); the physician asked them to fill out questionnaires and discussed existing problems with them on the basis of their answers (5\%). All the patients stated that the physician was interested in their well-being and existing symptoms.

In addition, significant differences between physicians and patients were revealed, regarding the time that physicians spent discussing blood test results and well-being with the patients. The vast majority of patients (93\%) believed that during the visit the physician spent most of the time discussing blood test results with them. At the same time, only $43 \%$ of physicians believed that they spent more time discussing blood test results with the patient rather than their wellbeing.

According to the survey of physicians, they received information about the patient's symptoms and overall well-being in the following way: $43 \%$ of physicians were actively interested in the patient's problems during the visit; $37 \%$ discussed the most important symptoms with the patient, and $13 \%$ expected reporting of any alarming symptoms from patients. Only $7 \%$ of physicians told that they asked patients to fill out questionnaires to record their symptoms. At the same time, 83\% of physicians stated that they assessed patient's symptoms at each visit. When evaluating the severity of symptoms, $43 \%$ of physicians considered the impact of disease on the daily life of the patient, and $27 \%$ of physicians based it on their own assessment. Only $20 \%$ of physicians used questionnaires for standard assessment of the symptoms.

\section{Disease impact on the quality of life in $\mathrm{Ph}(-)$ MPN patients}

The list of questions in the patient's and physician's survey checklists focused on the impact of symptoms on patient's quality of life and daily activities $[9,11]$. Most $\mathrm{Ph}(-) \mathrm{MPN}$ patients $(81 \%)$ believed that the symptoms reduced their quality of life (Table 2). All the MF patients, $65 \%$ of PV patients, and $75 \%$ of ET patients agreed with this statement. Physicians also shared the view that the disease symptoms lead to worsening of quality of life of patients. Furthermore, 77\% of physicians believed that even mild or moderate symptoms in patients could be associated with reduced quality of life.

As a special point, the effect of symptoms on daily life activities was evaluated by the survey. Figure 2 shows the distribution of the patient's and physician's answers about impact of the symptoms upon daily activities of patients, their family

Table 2. Symptom interference with quality of life in Ph(-) MPN patients

\begin{tabular}{|l|l|l|l|l|}
\hline Symptoms reduce my quality of life, \% & $\begin{array}{l}\text { MF } \\
(\mathbf{n = 1 5 )}\end{array}$ & $\begin{array}{l}\text { PV } \\
(\mathbf{n = 1 7 )}\end{array}$ & $\begin{array}{l}\text { ET } \\
(\mathbf{n}=\mathbf{8})\end{array}$ & $\begin{array}{l}\text { Whole sample } \\
(\mathbf{n}=\mathbf{4 0 )}\end{array}$ \\
\hline Strongly agree & 33 & 6 & 13 & 18 \\
\hline Somewhat agree & 67 & 59 & 62.5 & 62.5 \\
\hline Somewhat disagree & - & 23.5 & 24.5 & 14.5 \\
\hline Strongly disagree & - & 11.5 & - & 5 \\
\hline
\end{tabular}


and social life, relationships with caregivers, as well as limitations of activities caused by pain/discomfort. As evidenced in the Figure 2, most patients and physicians believed that disease symptoms affect the mentioned daily activities of patients. Most patients and physicians also indicated that pain/ discomfort limits patient's daily activities, especially in MF patients, compared to PV and ET. In MF, the reported symptoms had a higher impact on their daily activities, family and social life. Pain/discomfort also significantly limited their daily activities. In general, the discrepancy between physicians and patients in assessing the impact of disease symptoms on daily life was not significant.

\section{A}

My condition interferes with my daily activities

My condition interferes with my family and social life

Pain and discomfort interfere with my activities

My condition interferes with my relationship with caregivers

B

My condition interferes with my daily activities

My condition interferes with my family and social life

Pain and discomfort interfere with my activities

My condition interferes with my relationship with caregivers
The patients were also asked in what way the disease affected various aspects of their quality of life (Figure 3). For the vast majority of $\mathrm{Ph}(-) \mathrm{MPN}$ patients, the disease had a significant impact on physical (95\%) and emotional (87\%) functioning. Almost all of the patients (95\%) experienced anxiety, because of their condition and were worried that their condition would worsen. It is noteworthy that $80 \%$ of patients believed that their health was worse, if compared to their condition evaluated by treating physician, and $77 \%$ felt helpless.

As for different forms of $\mathrm{Ph}(-)$ MPNs, all the patients with MF and ET, as well as $88 \%$ of patients with PV, experienced
Physicians Patients

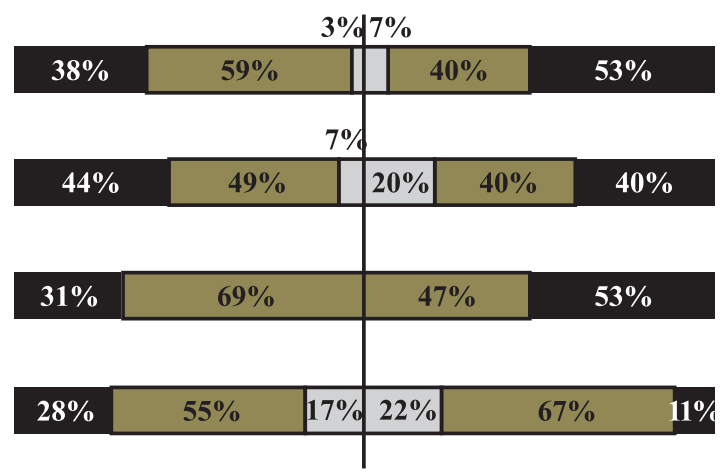

Physicians

Patients

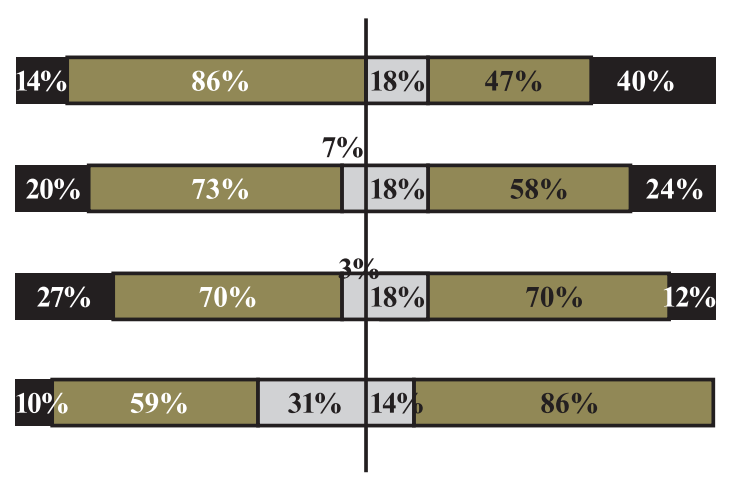

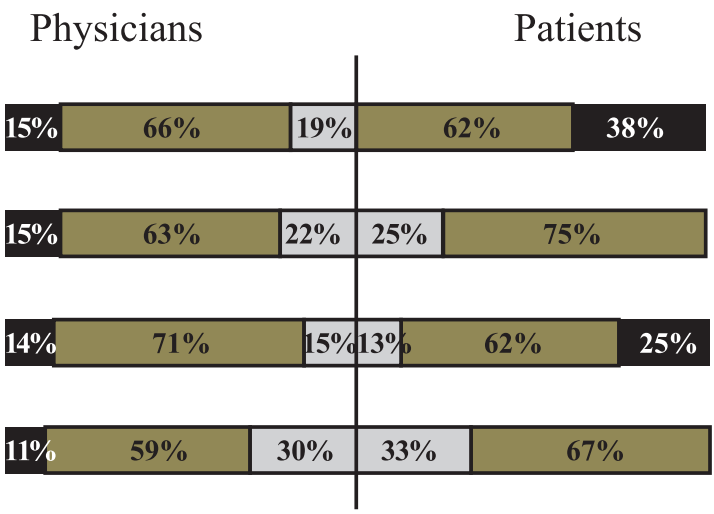

My condition interferes with my daily activities

My condition interferes with my family and social life

Pain and discomfort interfere with my activities

My condition interferes with my relationship with caregivers 
I feel helpless

I am satisfied with how I am coping with my condition

I have felt anxious about my condition

I have felt depressed

My condition has caused physical hardship for me

My condition has caused emotional hardship for me

My condition has caused financial hardship for me

I worry that my condition will get worse

I feel worse than my physician is aware of

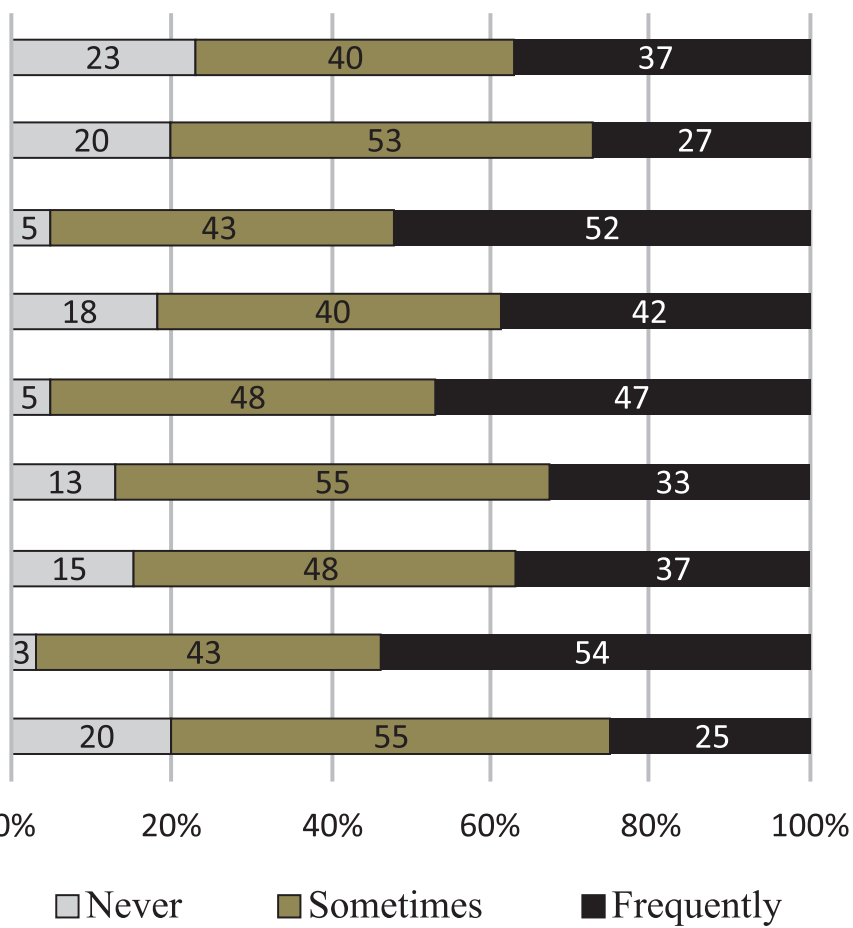

Figure 3. Disease impact on various aspects of quality of life as assessed by Ph(-) MPN patients

some degree of physical problems caused by their condition. All the ET patients, $87 \%$ of MF patients, and $82 \%$ of PV patients reported emotional burden associated with the disease. All the MF patients, $94 \%$ of PV patients and $87 \%$ of ET patients experienced anxiety related to their condition. At the same time, $93 \%, 71 \%$ and $75 \%$ of patients with MF, PV and ET, respectively, believed that they felt worse than perceived by their treating physician. Moreover, 93\%, 71\% and $62 \%$ of patients with MF, IP and ET, respectively, indicated that they felt helpless.

All surveyed physicians believed that MF and PV patients had physical and emotional limitations; $7 \%$ of physicians believed that ET patients did not experience such restrictions.

\section{Disease impact on work productivity in $\mathrm{Ph}(-)$ MPN patients}

The patient survey contained questions about employment, disability, limitations in overall activity and support from caregivers. From the proposed list of employment options, over one-third of patients $(35 \%)$ stated that they worked full time, $13 \%$ were in part-time employment, and $5 \%$ were on sick leave. Other patients claimed they were pensioners $(43 \%)$ or unemployed (6\%). Overall, $53 \%$ of patients reported that they continued to work at the time of the survey. Over past 7 days, the patients had to miss, on average, 2.8 hours of working time, due to their disease. To assess the impact of the disease on productivity at work and overall activity, patients were asked to choose a number on a scale from 0 to 10 , where 0 means "no effect of the disease on work/ overall activity" and 10 means "completely unable to work/ illness completely interferes with overall activity". According to the survey results, $32 \%$ of patients indicated that their disease significantly (score 7-10) limited their productivity at work; the disease significantly affected overall activity in $48 \%$ of patients.
Overall, $48 \%$ of $\mathrm{Ph}(-)$ MPN patients reported requiring assistance from a caregiver, with $46 \%$ of MF patients, $36 \%$ of PV patients and $13 \%$ of ET patients needed for support often or sometimes. Half of these patients were supported by their children. In $47 \%$ of cases, a support for the patients was provided by the people who continued to work. Assistance with housework (79\%) and transportation (74\%) were the main forms of support.

\section{Treatment of Ph(-) MPNs and physician's and patient's perspectives on treatment goals}

The surveys for physicians contained the following questions regarding treatment: 1) treatment strategy at the time of diagnosis; 2) therapy prescribed anytime in the past; 3) treatment that physicians currently prescribed for their patients. Physicians had to choose the answers from the proposed list of treatment options separately for patients with MF, PV and ET. According to their answers, the physicians chose a strategy of waiting and observation in $12 \%$ of MF patients, in $15 \%$ of PV cases, and in $18 \%$ of ET patients at the time of diagnosis. Details of previous treatment for patients with MF, PV and ET, and currently prescribed therapies, as well as reasons for changing therapy are summarized in Table 3. In general, there is no much difference between the past and current therapies prescribed by physicians to treat specific MF, PV and ET patients. Some differences between the past and current therapies were observed for MF treatment with epoetin- $\alpha$, androgens and glucocorticosteroids, for PV treatment with epoetin- $\alpha$, for ET treatment with glucocorticosteroids and BMT/HSCT.

Worth of note, half of the physicians reported an increase in symptoms of a specific $\mathrm{Ph}(-) \mathrm{MPN}$ as the reason for the change of treatment.

The questionnaire for physicians also included questions concerning prognostic risk assessment in patients with 
Table 3. Treatment prescribed in the past, currently prescribed therapy, and the reasons for changing therapy in patients with MF, IP and ET

\begin{tabular}{|c|c|c|}
\hline MF & Treatment prescribed in the past, \% & Currently prescribed therapy, \% \\
\hline Hydroxyurea & 86 & 83 \\
\hline Ruxolitinib & 66 & 48 \\
\hline Blood transfusions & 62 & 52 \\
\hline Epoetin-a & 62 & 34 \\
\hline Interferon- $a$ & 59 & 41 \\
\hline Androgens & 59 & 38 \\
\hline Iron replacement therapy & 45 & 28 \\
\hline Busulfan & 41 & - \\
\hline Glucocorticosteroids & 41 & 31 \\
\hline Psychotherapy & 38 & 24 \\
\hline Anticoagulants & 38 & 34 \\
\hline Splenectomy & 38 & - \\
\hline Antihistamines & - & 28 \\
\hline Acetylsalicylic acid & - & 28 \\
\hline \multicolumn{3}{|c|}{$\begin{array}{l}\text { Five most common reasons for changing treatment: disease progression (86\%), lack of efficacy }(79 \%) \text {, adverse events }(76 \%) \text {, cytopenia }(52 \%) \text {, } \\
\text { increase in symptoms ( } 41 \%) \text {, and changes in the hematopoietic system (41\%). }\end{array}$} \\
\hline PV & Treatment prescribed in the past, \% & Currently prescribed therapy, \% \\
\hline Phlebotomy & 90 & 86 \\
\hline Hydroxyurea & 86 & 86 \\
\hline Acetylsalicylic acid & 76 & 76 \\
\hline Anticoagulants & 48 & 34 \\
\hline Psychotherapy & 45 & 28 \\
\hline Antihistamines & 45 & 34 \\
\hline Iron replacement therapy & 38 & 14 \\
\hline Interferon- $a$ & 38 & 31 \\
\hline Epoetin-a & 28 & - \\
\hline Antidepressants & 28 & 21 \\
\hline Busulfan & 24 & 17 \\
\hline Ruxolitinib & 24 & 24 \\
\hline Nitrosoureas & 14 & 14 \\
\hline \multicolumn{3}{|c|}{$\begin{array}{l}\text { Five most common reasons for changing treatment: disease progression (76\%), adverse events (69\%), lack of efficacy }(59 \%) \text {, increase in } \\
\text { symptoms }(55 \%) \text {, and changes in the hematopoietic system (55\%). }\end{array}$} \\
\hline ET & Treatment prescribed in the past, \% & Currently prescribed therapy, \% \\
\hline Hydroxyurea & 85 & 81 \\
\hline Interferon- $a$ & 67 & 59 \\
\hline Anticoagulants & 67 & 67 \\
\hline Acetylsalicylic acid & 67 & 63 \\
\hline Anagrelide & 52 & 37 \\
\hline Psychotherapy & 41 & 33 \\
\hline Antidepressants & 30 & 26 \\
\hline Iron replacement therapy & 22 & 11 \\
\hline Busulfan & 22 & 19 \\
\hline Ruxolitinib & 22 & 22 \\
\hline Glucocorticosteroids & 19 & - \\
\hline Androgens & 15 & 7 \\
\hline BMT/HSCT & - & 15 \\
\hline
\end{tabular}


$\mathrm{Ph}(-) \mathrm{MPN}$, and criteria for assessing the disease progression. According to the survey, 70\% of physicians used different tools to calculate prognostic risk scores in their practice. IPSS was the most commonly used scale for assessing prognostic risk (43\%). Among those physicians who did not use the available risk assessment tools, 33\% considered these methods useful, but did not have enough time to use them in clinical practice; the same number of physicians (33\%) were familiar with these assessment tools, but did not consider them practically useful; $11 \%$ of physicians stated that they were not familiar with these tools. The physicians pointed to the following main criteria for the disease progression: in MF, deterioration of the patient's condition (86\%), increasing splenomegaly (86\%), and continued weight loss (79\%); in $\mathrm{PV}$, changes of hemoglobin levels (83\%), changing severity of symptoms (79\%), evolving new symptom(s) (72\%); in ET, changes in platelet levels (85\%), development of new symptom(s) (78\%), and deterioration of the patient's condition $(70 \%)$.

Both physicians and patients were given a separate block of questions related to the main treatment goals. Physicians and patients were asked to select the main treatment goals (except for a curation) from a list of statements. The physician and patient survey results regarding goals for $\mathrm{MF}$, PV and ET treatment are shown in Figure 4. Information is shown as the percentages of patients and physicians who have chosen the definite treatment goals. As seen in Figure 4, the MF, PV and ET patients have selected the following main treatment goals: better quality of life $(60 \%, 76 \%$, and $75 \%$, respectively), reduction of symptoms $(60 \%, 47 \%$, and $50 \%$, respectively), normal blood counts $(53 \%, 53 \%$, and $50 \%$, respectively), and slower progression of the disease (47\%, $41 \%$, $50 \%$, respectively). Physicians indicated the following main treatment goals (except for a cure) in $\mathrm{Ph}(-) \mathrm{MPN}$ patients: in MF, improved quality of life (66\%), slower disease progression (55\%) and reduction in spleen size (52\%); in PV and ET, better quality of life ( $69 \%$ and $59 \%$, respectively), prevention of thrombotic events ( $48 \%$ and $67 \%)$, retarded disease progression ( $48 \%$ and $48 \%$ ), and reduced frequency of phlebotomies in the PV patients (48\%).

In addition, the patients filled a list of supplementary statements on how successful or unsuccessful the treatment could be. When evaluating the success of treatment, patients used the following criteria: quality of life improvement or relief of symptoms (68\%), reduced number of the symptoms (48\%), physician's conclusion (48\%), and blood testing results $(43 \%)$.

Moreover, the physicians were also given a list of statements describing challenges in $\mathrm{Ph}(-) \mathrm{MPN}$ treatment. With regard to the treatment of MF, PV and ET patients, physicians selected the following unresolved issues: chances for cure $(41 \%, 31 \%$ and $41 \%$, respectively), and ability to delay progression of the disease $(21 \%, 21 \%$ and $19 \%$, respectively). Furthermore, $22 \%$ of physicians stated that a search for new effective drugs is an important aspect of ET treatment.

\section{Perception of the physician-patient relationship by physicians and $\mathrm{Ph}(-)$ MPN patients}

Both physician's and patient's surveys contained questions about patient satisfaction with the treatment, effectiveness of the physician in management of the disease, as well as the physician-patient relationship. In terms of treatment satisfaction, $98 \%$ of $\mathrm{Ph}(-) \mathrm{MPN}$ patients were generally satisfied with the treatment (65\% were completely satisfied and $33 \%$ were somewhat satisfied). Overall, $85 \%$ of patients were satisfied with efficiency of the disease control achieved by their physician (75\% were completely satisfied and $10 \%$ were somewhat satisfied). As for physicians, $90 \%$ of them were satisfied with their management of the disease. Similarly, $90 \%$ of physicians reported that their priority goals concerning treatment agreed with the patients' perspectives: $37 \%$ believed that they completely agreed, 53\% agreed to some extent. In general, all the patients were satisfied with the communication with their physician. When asked about the physician-patient relationship, $84 \%$ of physicians stated that they were satisfied with their communication with patients. Whereas $95 \%$ of patients indicated that they were generally satisfied with the awareness of various aspects of the disease, $5 \%$ were not satisfied. When asked about patient awareness of the disease, $87 \%$ of physicians believed that patients were well informed.

The majority of patients (95\%) reported that they received information about their disease directly from their physician; $20 \%$ of patients indicated that they had difficulties with finding information about their disease.

\section{Discussion}

This paper presents data on survey of Russian patients and physicians evaluating the impact of chronic $\mathrm{Ph}(-)$ MPNs on various aspects of patients' well-being, conducted as a part of the international Landmark Survey. One of the main aims of the Landmark Survey is to study the symptoms experienced by $\mathrm{Ph}(-)$ MPN patients and their impact on daily activities as assessed by patients and physicians. The survey was also designed to investigate how the disease affects the patient's quality of life and work productivity, both from the patient's and physician's perspective. The analysis was based on the survey completed by 40 patients with $\mathrm{Ph}(-) \mathrm{MPN}$ and 30 attending physicians.

The results of the survey revealed a significant impact of $\mathrm{Ph}(-)$ MPNs on quality of life of the patients. Accordingly, the disease symptoms in majority of $\mathrm{Ph}(-) \mathrm{MPN}$ patients (100\% of MF cases, $65 \%$ of PV cases, and $75 \%$ of ET patients), led to impairment of their quality of life. In general, these data are consistent with results of the original Landmark study conducted in the USA, where $81 \%$ of MF patients, $66 \%$ of PV patients and $56 \%$ of ET patients reported worsening of their quality of life due to the disease [8]. However, compared with the original study, a higher number of MF (100\% versus $81 \%$ ) and ET (75\% versus $56 \%$ ) patients in the Russian sample reported the negative effect of the disease symptoms on their quality of life.

In terms of the most common symptoms after diagnosis, $\mathrm{Ph}(-)$, the MPN patients noted fatigue $(63 \%)$ and weakness (53\%), thus being consistent with the data from the Landmark Survey in other countries [8-11]. It is worth of note that over a half of the patients (54\%) experienced symptoms for a year prior to diagnosis, and the remaining patients had 
MF

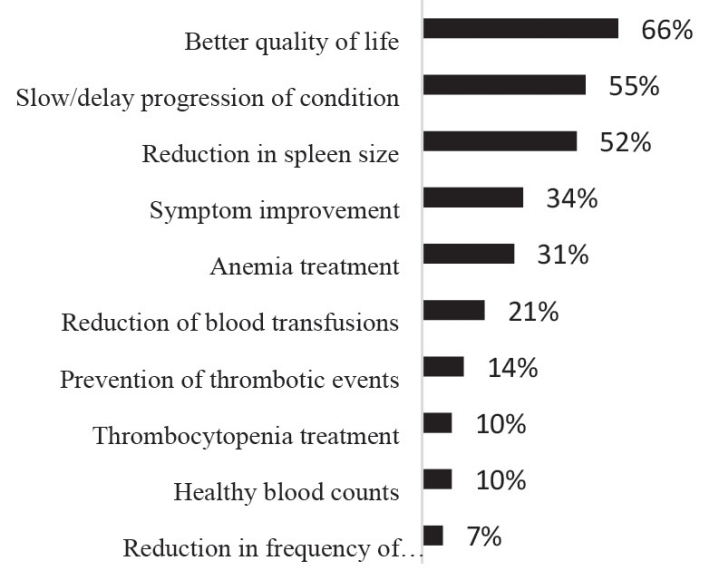

- Physician perception, $\mathrm{n}=29$

PV

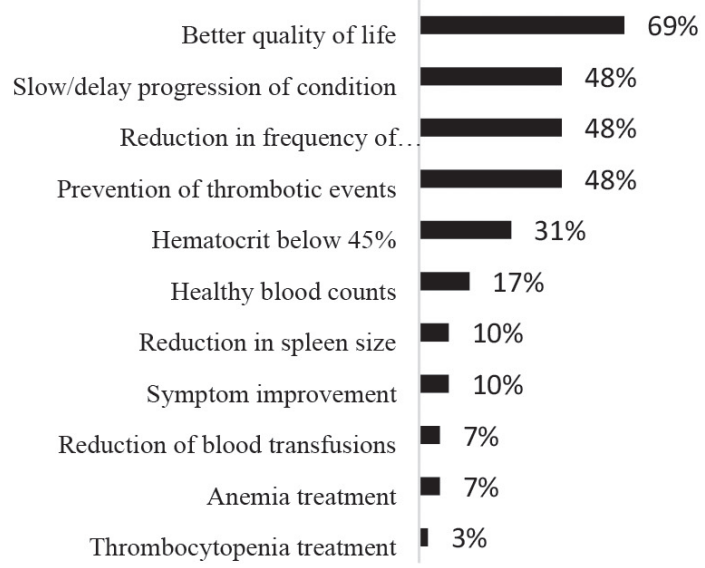

- Physician perception, $\mathrm{n}=29$

\section{ET}

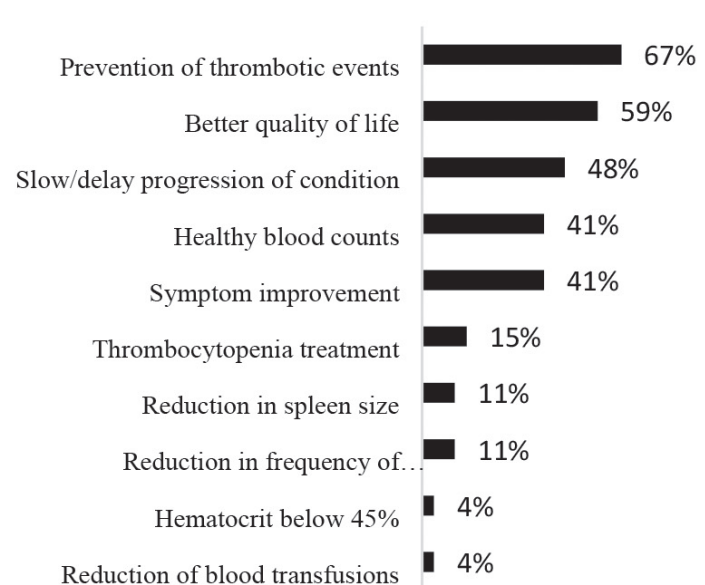

MF

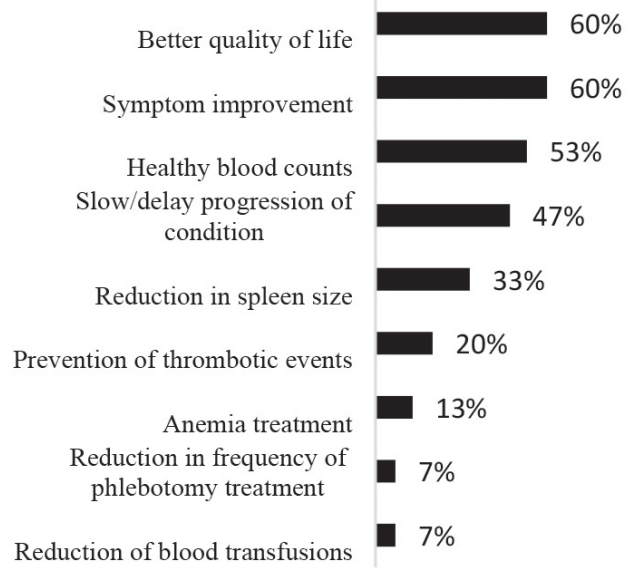

- Patient perception, $\mathrm{n}=15$

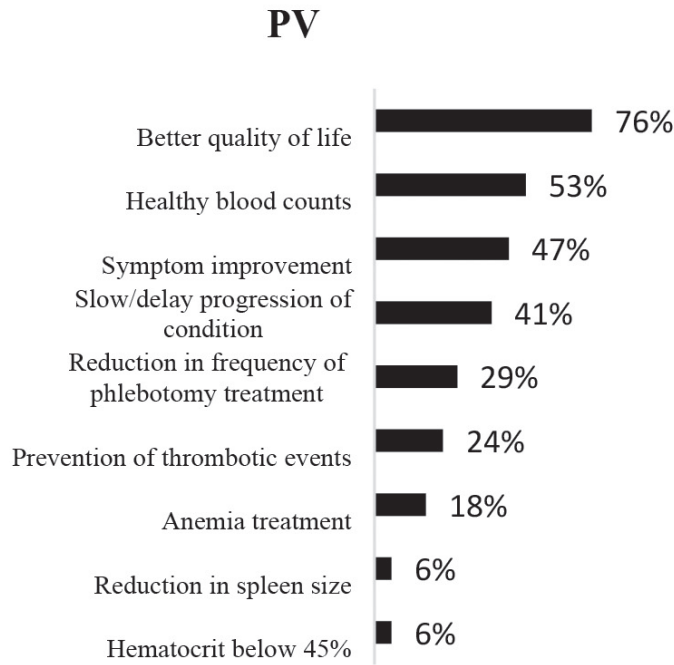

- Patient perception, $\mathrm{n}=15$

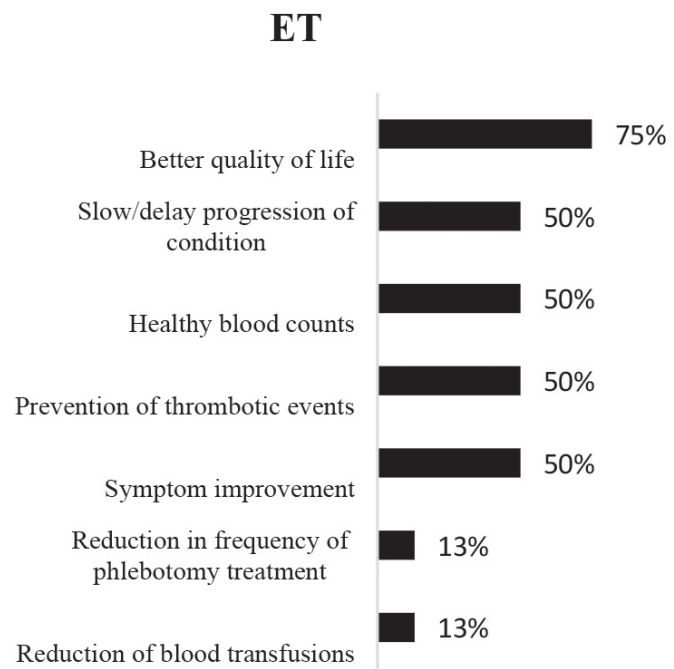

- Physician perception, $\mathrm{n}=27$

- Patient perception, $\mathrm{n}=8$

Figure 4. Ph(-) MPN treatment goals (other than cure), as reported by physicians and patients 
symptoms for two or more years before receiving the diagnosis, which is significantly more than in other countries [8-10].

When analyzing the symptoms exhibited by $\mathrm{Ph}(-)$ MPN patients over the past 12 months, it was shown that most patients, regardless of the disease, noted weakness or fatigue. Other common symptoms were different, depending on the specific $\mathrm{Ph}(-)$ MPN subtype. It is important to note that not all patients believed these symptoms were related to the disease.

This data is in line with the published results of Landmark survey in the countries with development markets according to which many patients also did not recognize that their symptoms could be MPN-related. For example, in this study $18 \% \mathrm{MF}$ and 25\% PV did not think their fatigue/tiredness resulted from MPNs [10]. According to our data, 33\% and $14 \%$ of MF and PV patients, respectively, did not recognize fatigue as a symptom of the disease. It should also be noted that the analysis of the physician's and patient's responses regarding the most important patient's symptoms revealed a discrepancy in their assessments. To some extent, these differences can be explained by the fact that only a half of the physicians actively discussed well-being and symptoms with patients during clinic visits. Moreover, the results show that only $20 \%$ of asked physicians use standardized questionnaires to assess the severity of symptoms, i.e., a significantly smaller proportion compared to their colleagues in other countries [8-10].

The analyzed results of the patient's and physician's surveys evaluating the effect of disease symptoms on daily lives of patients, including their everyday activities, family or social life, relationships with caregivers, and pain/discomfort that limits activity, revealed that, in the opinion of most patients and physicians, the disease burden affects daily lives of patients. It is worth of note that, in general, the discrepancy between physicians and patients in assessing the impact of disease symptoms on daily life was not significant. These results are consistent with previous reports that included non-US patients [12-14], as well as the recent US Landmark survey [6].

In a separate subset of questions, patients and physicians evaluated how the disease affected various aspects of their physical and emotional functioning. In the overwhelming majority of cases both patients and physicians reported that the disease caused significant physical and emotional hardship for $\mathrm{Ph}(-) \mathrm{MPN}$ patients. The following data requires a special consideration: almost all the patients experienced anxiety because of their condition and were worried that their condition would worsen; moreover, $80 \%$ believed that their health was worse than what their treating physician perceived.

It was also shown that $\mathrm{Ph}(-) \mathrm{MPNs}$ affect working ability and overall activity of patients. Thus, $32 \%$ of patients indicated that their disease significantly (score 7-10) limited their productivity at work; the disease had a significant impact on the overall activity of $48 \%$ of patients. Similar data was collected by the Landmark Survey in other countries [11].

Overall, almost a half of $\mathrm{Ph}(-) \mathrm{MPN}$ patients reported requiring assistance from a caregiver, with $46 \%$ of MF patients,
$36 \%$ of PV patients and $13 \%$ of ET patients needing support often or sometimes. These results are consistent with data obtained in other countries [11].

A separate analysis was conducted on the responses of physicians regarding treatment strategies at the time of diagnosis, treatments that were prescribed in the past, and treatments currently prescribed for their patients. It is interesting to note that half of the physicians reported an increase in symptoms as the reason for changing treatment, which emphasizes the importance of improving approaches to symptom management in $\mathrm{Ph}(-) \mathrm{MPN}$ patients.

Responses of physicians on the approaches of $\mathrm{Ph}(-) \mathrm{MPN}$ prognostic risk assessment were also analyzed. It should be noted that $70 \%$ of physicians used different tools to assess prognostic risk in their practice, but a third of physicians did not resort to their use due to lack of time, doubts about the usefulness of these tools or simply due to insufficient information about them.

Patient's and physician's responses regarding the MF, PV and ET therapy goals are of particular interest. It is important to note that both patients and physicians chose the improvement of the quality of life and symptom relief, as well as slowing the progression of the disease as the main treatment goals. In terms of evaluating treatment success, most patients (68\%) mentioned the improvement in quality of life and symptom relief. This fact highlights the relevance of patient quality of life assessments as one of the important treatment outcomes. Besides, the international guidelines on assessing clinical response of $\mathrm{Ph}(-) \mathrm{MPN}$ patients to treatment suggest the use of information on patient's quality of life and symptoms $[15,16]$.

Satisfaction with the treatment as well as with the physician-patient relationship was also analyzed. With regard to the physician-patient relationship, $84 \%$ of physicians and $100 \%$ of patients were satisfied with it. According to the majority of the physicians (87\%), patient awareness of the disease was rather high. Overall, $95 \%$ of patients were satisfied with their knowledge of the various aspects of the disease. At the same time, the issues identified in the survey of physicians and patients in relation to significant discrepancies between physician's and patient's assessment of burdensome symptoms, and specific perception of certain symptoms as not related to their disease by the patients highlight the importance of further improvement of symptom assessment strategies in $\mathrm{Ph}(-) \mathrm{MPN}$ patients and raising awareness about the disease among the medical community, $\mathrm{Ph}(-)$ MPN patients and their relatives.

Despite the fact that the results were obtained in a limited sample of respondents (40 patients with $\mathrm{Ph}(-) \mathrm{MPN}$ and 30 physicians), it is the first comprehensive analysis of the problems associated with the disease and treatment of $\mathrm{Ph}(-)$ MPN obtained in the Russian population of these patients, and the information is presented from the viewpoint of both patients and physicians. In general, the results of our survey demonstrate that patients with $\mathrm{Ph}(-)$ MPN feel a significant negative impact of the disease on various aspects of their life, have impaired quality of life and reduced work productivity. This data confirm the previously published results of the 
Landmark Survey conducted in other countries [6-11]. At the same time, this analysis enabled us to identify features of the disease impact and treatment upon various aspects of daily life of $\mathrm{Ph}(-)$ MPN patients in Russia, to describe their perceptions of the treatment goals, to assess the degree of satisfaction with treatment and disease control, and also to gain an insight into the physician-patient relationship and the strategies that physicians use in real clinical practice to obtain information about the impact of the disease and treatment on various aspects of the patient's life. Overall, the results obtained support the value of patient's perspective about the disease and its treatment for $\mathrm{Ph}(-)$ MPN to improve quality of care of this patients' population [17-19].

\section{Conclusion}

Evaluation and synthesis of the survey data collected among Russian $\mathrm{Ph}(-) \mathrm{MPN}$ patients and their attending physicians as part of the Landmark Survey constitute an important contribution to this project conducted in different countries. This data revealed that the patients with different $\mathrm{Ph}(-)$ MPNs have serious disease-related restrictions in everyday life, altered quality of life and reduced work productivity. In addition, the survey has revealed discordance in physician's and patient's assessment of the problems that patients face in relation to the disease and treatment. These differences indicate a need for new approaches, in order to improve of quality of care for this patients' population, as well as for raising knowledge on the $\mathrm{Ph}(-) \mathrm{MPNs}$ among the medical community and patients. Further clinical research is required to substantiate the development of patient-centered treatment programs for chronic Ph-negative myeloproliferative neoplasms in Russian Federation, as well as to provide detailed information for the patients and their relatives about the disease and its treatment.

\section{Acknowledgements}

No conflict of interest declared.

\section{References}

1. Melikyan AL, Kovrigina AM, Subortseva IN, Shuvaev VA. National clinical recommendations on diagnostics of Ph-negative myeloproliferative diseases (polycythemia vera, essential thrombocytemia, primary myelofibrosis), revised 2018. Gematologiya I Transfuziologiya. 2018; 3:275-315 (In Russian).

2. Geyer JT, Orazi A. Myeloproliferative neoplasms (BCRABL1 negative) and myelodysplastic/myeloproliferative neoplasms: current diagnostic principles and upcoming updates. Int J Lab Hematol. 2016; 38 Suppl 1: 12-19.

3. Pemmaraju N, Clementi T, Qiao W, Peterson SK, Zoeller V, Schorr AJ, Verstovsek S. Myeloproliferative neoplasm (MPN) patient online questionnaire: assessing patients' disease knowledge in a rare hematologic malignancy in the modern digital information era. Blood. 2019; 134 (Supplement 1): 1670.

4. Kurtin S, Lyle L. The role of advanced practitioners in optimizing clinical management and support of patients with polycythemia vera. J Adv Pract Oncol. 2018; 9(1): 56-66.
5. Mesa RA, Passamonti F. Individualizing care for patients with myeloproliferative neoplasms: integrating genetics, evolving therapies, and patient-specific disease burden. 2016 ASCO Educational Book: e324-e335.

6. Mesa R, Miller CB, Thyne M, Mangan J, Goldberger S, Fazal S. et al. Myeloproliferative neoplasms (MPNs) have a significant impact on patients' overall health and productivity: the MPN Landmark survey. BMC Cancer. 2016; 16: 167.

7. Mesa RA, Miller CB, Thyne M, Mangan J, Goldberger S, Fazal S, Ma X, Wilson W, Paranagama DC, Dubinski DG, Naim A, Parasuraman S, Boyle J, Mascarenhas JO. Differences in teatment goals and perception of symptom burden between patients with myeloproliferative neoplasms (MPNs) and hematologists/oncologists in the United States: findings from the MPN Landmark Survey. Cancer. 2017; 123(3): 449458.

8. Yu J, Parasuraman S, Paranagama D, Bai A, Naim A, Dubinski D, Mesa R. Impact of myeloproliferative neoplasms on patients' employment status and work productivity in the United States: results from the living with MPNs survey. BMC Cancer. 2018; 18(1): 420. DOI: 10.1186/s12885-0184322-9.

9. Harrison CN, Koschmieder S, Foltz L, Guglielmelli P, Flindt T, Koehler M. Mathias JP, Komatsu N, Boothroyd RN, Spierer A, Ronco JP, Taylor-Stokes G, Waller J, Mesa R. The impact of myeloproliferative neoplasms (MPNs) on patient quality of life and productivity: results from the international MPN Landmark survey. Ann Hematol. 2017; 96 (10): 16531665. doi: 10.1007/s00277-017-3082-y.

10. Xiao Z, Chang CS, Morozova E, Bang SM, Alzahrani M, Mycock K, Rajkovic I, Siddiqui A, Saydam G. Impact of myeloproliferative neoplasms (MPNs) and perceptions of treatment goals amongst physicians and patients in 6 countries: an expansion of the MPN Landmark Survey. HemaSphere. 2019; Volume 3 (S1): 294-295. DOI: 10.1097/01. HS9.0000561008.75001.e7.

11. Saydam G, Chang C, Morozova E, Bang S, Alzahrani M, Mycock K, Rajkovic I, Siddiqui A, Xiao Z. Impact of myeloproliferative neoplasms (MPNs) and perceptions of treatment goals amongst physicians and patients in 6 countries: an expansion of the MPN Landmark Survey. Leukemia Res; 2019; 85 (Suppl 1): S60-S61.

12. Emanuel RM, Dueck AC, Geyer HL, Kiladjian JJ, Slot S, Zweegman S, te Boekhorst PAV, Commandeur S, Schouten HC, Sackmann F, Fuentes AK, Hernández-Maraver D, Pahl HL, Griesshammer $\mathrm{M}$ et al. Myeloproliferative neoplasm (MPN) symptom assessment form total symptom score: prospective international assessment of an abbreviated symptom burden scoring system among patients with MPNs. J Clin Oncol. 2012; 30(33): 4098-4103.

13. Abelsson J, Andreasson B, Samuelsson J, Hultcrantz M, Ejerblad E, Johansson B, Emanuel R, Mesa R, Johansson P. Patients with polycythemia vera have worst impairment of quality of life among patients with newly diagnosed myeloproliferative neoplasms. Leukemia \& lymphoma. 2013; 54(10): 2226-2230. 
14. Scherber R, Dueck AC, Johansson P, Barbui T, Barosi G, Vannucchi AM, Passamonti F, Andreasson B, Ferarri ML, Rambaldi A, Samuelsson J, Birgegard G, Tefferi A, Harrison CL, Radia DH, Mesa R. The myeloproliferative neoplasm symptom assessment form (MPN-SAF): international prospective validation and reliability trial in 402 patients. Blood. 2011; 118(2): 401-408.

15. NCCN Clinical Practice Guidelines in Oncology (NCCN Guidelines $^{\circledR}$ )/Myeloproliferative Neoplasms. Version 2.2019October 29, 2018. NCCN.org

16. Barosi G, Mesa R, Finazzi G, Harrison CN, Kiladjian JJ, Lengfelder E, McMullin MF, Passamonti F, Vannucchi AM, Besses C, Gisslinger H, Samuelsson J, Verstovsek S, Hoffman R, Pardanani A, Cervantes F, Tefferi A, Barbui T. Revised response criteria for polycythemia vera and essential thrombocythemia: an ELN and IWG-MRT consensus project. Blood. 2013; 121 (23): 4778-4781.
17. Guidelines. Patient-reported outcomes in hematology. EHA SWG "Quality of life and Symptoms". Forum Service Editore. Genoa, 2012. 206 p.

18. Mesa RA, Niblack J, Wadleigh M, Verstovsek S, Camoriano J, Barnes S, Tan AD, Atherton PJ, Sloan JE, Tefferi A. The burden of fatigue and quality of life in myeloproliferative disorders (MPDs): an international Internet-based survey of 1179 MPD patients. Cancer. 2007; 109 (1): 68-76.

19. Zander AR. Stem cell transplantation for myeloproliferative diseases in the era of molecular therapy. Cell Ther Transplant. 2017; 6(4):21-27.

\title{
Отношение к заболеванию и лечению у пациентов с хроническими Ph-негативными неоплазиями: результаты опросов врачей и их пациентов в России, как часть международного исследования Landmark
}

\author{
Елена В. Морозова ${ }^{1}$, Мария В. Барабанщикова ${ }^{1}$, Татьяна И. Ионова $^{2}$, Борис В. Афанасьев $^{1}$ \\ ${ }^{1}$ НИИ детской онкологии, гематологии и трансплантологии им. Р. М. Горбачевой, Первый Санкт-Петербургский \\ государственный медицинский университет им. акад. И. П. Павлова, Санкт-Петербург, Россия \\ 2 Санкт-Петербургский государственный университетский госпиталь, Санкт-Петербург, Россия
}

\section{Резюме}

Целью данной статьи была оценка и обобщение данных, полученных при опросах российских больных и их лечащих врачей, проведенных в рамках международного исследования Landmark для стран с развивающимся рынком, направленного на выяснение проблем и вопросов ведения пациентов с хроническими Рh-негативными миелопролиферативными новообразованиями (МПН). Разосланные онлайн-формы заполняли 40 взрослых пациентов c $\mathrm{Ph}(-) \mathrm{MПН} \mathrm{(истинная} \mathrm{полицитемия} \mathrm{-} 42,5 \%$; миелофиброз - 37,5\%; эссенциальная тромбоцитемия $20 \%)$, а также 30 врачей с достаточным опытом лечения $\mathrm{Ph}(-)$ МПН. В рамках этого исследования, лечащие врачи и пациенты отвечали на вопросы, касающиеся восприятия симптомов заболевания и их воздействия на качество жизни, повседневную активность и продуктивность работы пациентов, а также их отношения к основным целям терапии и различным аспектам общения больного и врача. Результаты: выявлен ряд различий между воспри- ятием заболевания и лечения больными и врачами, что дополняет данные исследования Landmark, полученные в других странах. Было показано, что больные с различными вариантами $\mathrm{Ph}(-) \mathrm{MПH}$ сталкиваются со значительными проблемами в повседневной жизни, нарушениями качества жизни и снижением работоспособности, обусловленными заболеванием. Отсутствие совпадения в оценке тяжести и лечения болезни врачом и больным указывает на необходимость новых подходов к улучшению качества клинического обслуживания для этой категории больных. Дальнейшие исследования в этой области были бы важным шагом к внедрению в Российской Федерации программ лечения $\mathrm{Ph}(-)$ МПН, ориентированных на больных.

\section{Ключевые слова}

Миелопролиферативные неоплазии, хронические, $\mathrm{Ph}$-негативные, опрос пациентов и врачей, симптомы, качество жизни, пациент-ориентированные программы. 